\title{
Assessment of the HIV Infection Prevention Methods Preference and Its Associated Factors Among Debre Birhan University Students
}

\author{
Addis Adera ${ }^{1,}$ *, Yonas Yimam ${ }^{1}$, Kenean Getaneh ${ }^{1}$, Tefera Mulugeta ${ }^{2}$, Mullu Hailu , \\ Ambachew Woreta ${ }^{3}$, Markos Kidane ${ }^{4}$ \\ ${ }^{1}$ Department of Nursing, Faculty of health Sciences, Woldia University, Woldia, Ethiopia \\ ${ }^{2}$ Department of Nursing, College of Medicine and Health Sciences, Debre Birhan University, Debre Birhan, Ethiopia \\ ${ }^{3}$ Department of Biology, Faculty of Natural and Computational Sciences, Woldia University, Woldia, Ethiopia \\ ${ }^{4}$ Department of Economics, Faculty of Business and Economics, Unity University, Addis Ababa, Ethiopia
}

Email address:

addisaderagebru@gmail.com (G. A. Adera)

\section{To cite this article:}

Addis Adera, Yonas Yimam, Kenean Getaneh, Tefera Mulugeta, Mullu Hailu, Ambachew Woreta, Markos Kidane. Assessment of the HIV Infection Prevention Methods Preference and Its Associated Factors Among Debre Birhan University Students. American Journal of Health Research. Vol. 3, No. 4, 2015, pp. 213-220. doi: 10.11648/j.ajhr.20150304.13

\begin{abstract}
Background: Significant proportions of the youth including university and college students are at high risk of HIV infection despite high level of knowledge about HIV/AIDS. In adolescents and youth population, HIV prevention will be relatively easy when strategies are designed to be in compatible with their desire. Currently, attention has been focused on the promotion of the "ABCs" of HIV prevention (being abstinent, remaining faithful to one sexual partner, and using condoms consistently during sexual intercourse).Objective: To assess the HIV infection prevention method preference and its association factors among Debre Birhan University Students. Method: Using an Institutional crossectional descriptive study was carried out by administering pre-tested self-administered questionnaires for selected students those included in the study by stratified sampling followed by simple random sampling. The data was collected from May 3-6/2013 from 390 regular students of Debre Berhan University. There were five data collector and one coordinator during the data collection. After data collection, the data was checked for its completeness, descriptive frequency tables were constructed and also some associations between variables were analyzed by chi-squared test and crude odds ratio. Lastly, conclusion and recommendation were forwarded based on the result. Result: From the total 390 respondents who were attended their study in Debre Berhan University, 195(50\%) of them were preferred to be abstain from sex followed by $117(30 \%)$ be faithful to one sexual partner and $78(20 \%)$ used condom properly and consistently. 190(48.72\%) of the total respondents reported that Abstinence as the safest prevention method for university and higher institute followed by Condom use 133(34.1\%) and Be faithful and 67(17.18\%). The respondents were also forwarded their opinion about the most widely used prevention method in this university. According to this, Condom use was reported by $307(78.72 \%)$, Abstinence 47(12.05\%) and be faithful 36(9.22\%). Being female, not engaging on watching pornographic movies and gaining relatively low amount of pocket money (income) per month were highly associated with to be abstaining from sex. Conclusion: Half of students in Debre Berhan University were preferred to use Abstinence from sex in order to protect themselves from HIV/AIDS infection. Despite around half of the respondent was agreed that abstinence is the safest prevention method for university and higher educational institutes' students, majority of the total respondents reported that condom use was widely applicable in the campus.
\end{abstract}

Keywords: HIV, Infection Prevention Method, Preference, HIV Infection Associated Factors

\section{Introduction}

HIV/AIDS is a world tragedy, affecting every country in the world, and has no boundary. At the end of 2010, an established
34 million people $[31,600,000-35,200,000]$ were living with HIV globally, including 3.4 million [3,000,000-3,800,000] children less than 15 years. There was 2.7 million $[2,400,000-2,900,000]$ new HIV infection in 2010, including 390,000 [340,000-450,000] among children less than 15 years 
(1). A number of studies have showed that AIDS has progressively been on the increasing and constitute a big problem among college and University students, although the extent of the problem is relatively unknown (2). Few studies showed assessed the attitude of sexual activity, risk perception and prevention method among university and college students .For instance, the study was conducted in USA, state of California, J.B Elgar University, department of medicine showed that from a total 3651 study subjects (university students) who have heard about HIV/AIDS and also know their sero-status for HIV, 4.52\% (165) use abstinence before marriage, $22.3 \%$ (814) be faithful with their partners, $65.06 \%$ (2375) use condom properly and consistently and the remaining $8.12 \%$ (297) were use none of the above methods (3). Among students in university of Zululand, Swithrland, consistent condom was the most commonly reported way to protect oneself from HIV/AIDS, mentioned by $68 \%$ of respondents. This was the only prevention method that those students named more frequent than other groups. Abstaining from sex was the second most commonly named prevention method, and was the only other method named by nearly majority of respondents $(19.6 \%)$. Limiting the number of sexual partners or having only one sexual partner was the next most commonly named prevention methods, mentioned by nearly a quarter of respondents $(12.3 \%)(4,5,6)$. The research conducted in South Africa, university of Oklahoma, the frequently mentioned prevention methods were, in order, condom use (mentioned by $88 \%$ of respondents), abstinence $(47 \%)$ and be faithful $(23 \%) \%)(7)$.

In another published result, in Uganda, $57 \%$ of students in six Universities have been involved in recent sexual activity (i.e. had sexual intercourse in the 12 months preceding the survey); about $74 \%$ of the students who have ever had sexual intercourse had had sexual intercourse in 12 months preceding survey. This implies that about one quarter of the students who have ever had sexual intercourse were practicing abstinence. The median age at the first sex for students was 18 years, and was higher among female students (19 years). Only 59\% of the students who ever had sex used a condom at their first sexual intercourse (8). HIV prevention strategies, which couldn't fit with the targets group desire, have higher tendency of to be neglected and fail to achieve their goal. When strategies are drafted, especially for adult population, they need to be compatible with their current need and also supported with the available technology and resource. In most African countries more than $34 \%$ (in average) of population takes health education about the HIV prevention strategies in public mass media daily. But more than half of them are less interested in the health education and also $20 \%$ of them take health education while they don't have interest to implement it $(9,10)$. According to the above finding, we analyze that, knowing the students' preventive method preference is important to focus on the acceptable and commonly used method of HIV prevention strategies to reduce the transmission of the infection in our campus and to allocate health service resources efficiently. But in our campus, there is no research conducted on this topic, even though, the issue is helpful to identify the preferred method and enable the responsible bodies and stakeholders to modify their preventive service approaches accordingly. Hence the aim of this study is to assess the method of preference to prevent HIV infection and its association factors among Debre Berhan University Students.

\section{Methods and Materials}

An institutional based descriptive, cross-sectional study was done from May 15-25, 2013.DebreBerhan University, one of those newly established Universities in Ethiopia in 2007.It is found in Amhara region, Debre Berhan town, and $130 \mathrm{~km}$ from Addis. Currently it has the capacity to accommodate about 8810 regular students in 7 faculties and more than 30 departments. Debre Berhan University students. The study population were regular students from all faculty of the university those selected by our sampling procedure. All Debre Berhan University regular students were included in this study. Students on field work at data collection time, severely ill students and all extension and summer program students were excluded. The sample size for the quantitative data was computed based on the formula proposed by Hollander (1999) for single population proportion. The value of $p$ was taken as $57 \%$ of abstain from sex (the most preferred prevention method) based on a previous knowledge, attitude and practice study conducted among Jimma University students. The source population, Debre Berhan University, have seven faculties which can be considered each faculty as strata because they have similarities with in the faculty and difference among them. We included all faculties of the university to keep the representativeness of the result. Then from each faculty we selected single department by simple random sampling. Then we included all batches of each selected department. From each batch's sections were drawn by simple random sampling. Lastly we selected the study units (students) from all selected sections by simple random sampling. The proportional allocation of the study units were determined at department and batch level using the formulanj $=\mathrm{n} / \mathrm{N} \times \mathrm{Nj}$. Wherenj=number of study participants; $\mathrm{n}$ $=$ adjusted sample size; $\mathrm{N}=$ number of source population; $\mathrm{Nj}$ $=$ total number of jthstrata. 397 students Where, PPRprobability proportionate by size

The data collection tool was self-administered, semi-structured questionnaire, which include both closed and open ended questions. The questionnaire contains questions about the socio demographic status of the respondent's knowledge about HIV/AIDS and the respondent's prevention method preference against HIV.There were five data collectors and one supervisor which coordinate and arrange the data collection process. The questionnaire was filled by the respondents on their class level from May 3- 6/2013 GC.HIV infection prevention method preferred by the students were dependent variable. However, Socio demographic characteristics: age, sex, residence, academic year, income; Behavioral characteristics: Presence of sexual partner, Prior sexual experiences, kaht chewing and other drugs use, 
pornographic movies and religious affairs also as other variables9confunding variables). After data collection, responses were checked for their completeness. Descriptive Frequency statistics was employed to describe the study population in relation to relevant variables. Contingency tables like chi-squared test and odds ratio were used to see the association between the dependent and outcome variables. The questionnaire was pre tasted before the beginning of the actual data collection on 39 students ( $10 \%$ of the sample unit) in Victory College, which have almost similar environment with this study population. Adjustment was done based on the pre-test result for the tools appropriateness and intensifies its validity. The questionnaire was first prepared in English language and then translated to Amharic for the data collection. Lastly translate back to English to keep its consistency for data analysis. Throughout the data collection supervision was done by supervisor to keep the quality of the data to its maximum. During the data collection, the data collector verified any unclear and misunderstood questions and the way of answering to the questions to the respondents. Ethical clearance was obtained from Debre Berhan University Nursing Department research committee and privacy of each client was assured with informed verbal consent before data collection. On the questionnaire, respondents were notified that their name has not be posted or required to be filled. Each respondent was also allowed to withdraw themselves from the study if they feel not confidential about the data security. The research paper was disseminated to those concerned bodies including Debre Berhan University nursing department office, Debre Berhan University HIV/AIDS Resource center, Debre Berhan University students' affairs office, Debre Berhan University Gender office and HAPCO.

\section{Result}

From the total sample size which was 397 , those 390 students in Debre Berhan University were involved in this finding (non respondent rate $1.76 \%$ ). Among those respondents $181(46.41 \%)$ were join the university from urban areas and the rest 209 (53.59\%) were from rural areas. Table 1 below describes the socio demographic status of the students those participated on the study.

Table 1. Socio demographic status of the respondents' on Assessment of HIV prevention method preference and its association factors among students in Debre Berhan University, May 2013.

\begin{tabular}{|c|c|c|c|}
\hline S.No & Variables & & N (\%) \\
\hline \multirow{5}{*}{1} & \multirow{5}{*}{ Age } & $15-19$ & $118(30.26)$ \\
\hline & & $20-24$ & $253(64.87)$ \\
\hline & & $25-29$ & $17(4.36)$ \\
\hline & & $30-34$ & $2(0.51)$ \\
\hline & & Total & 390 \\
\hline \multirow{3}{*}{2} & \multirow{3}{*}{ Sex } & Male & $209(53.59)$ \\
\hline & & Female & $181(46.41)$ \\
\hline & & Total & 390 \\
\hline \multirow{3}{*}{3} & \multirow{3}{*}{ Residence } & Urban & $181(46.41)$ \\
\hline & & Rural & 209 (53.59) \\
\hline & & Total & 390 \\
\hline \multirow{5}{*}{4} & \multirow{5}{*}{ Batch } & $1^{\text {st }}$ year & $101(25.9)$ \\
\hline & & $2^{\text {nd }}$ year & $66(16.92)$ \\
\hline & & $3^{\text {rd }}$ year & $207(53.08)$ \\
\hline & & $4^{\text {th }}$ year & $16(4.1)$ \\
\hline & & Total & 390 \\
\hline \multirow{5}{*}{5} & \multirow{5}{*}{$\begin{array}{l}\text { Monthly pocket } \\
\text { money (income) }\end{array}$} & $<500$ birr & $229(57.71)$ \\
\hline & & 500-1000birr & $97(24.88)$ \\
\hline & & $>1000$ birr & $14(3.59)$ \\
\hline & & No birr at all & $50(12.82)$ \\
\hline & & Total & 390 \\
\hline
\end{tabular}

Among 390 respondents $388(99.49 \%)$ of them had knowledge about HIV/AIDSs. Regarding to knowledge about the three HIV infection prevention methods namely; abstinence, be faithful and use condom all the respondents had knowledge. The figure 1 below shows the students current prevention method preference at the data collection time. According to this, 195(50\%) of them preferred Abstain from sex as their top prevention method followed by be faithful to one partner $117(30 \%)$, and Condom use $78(20 \%)$.

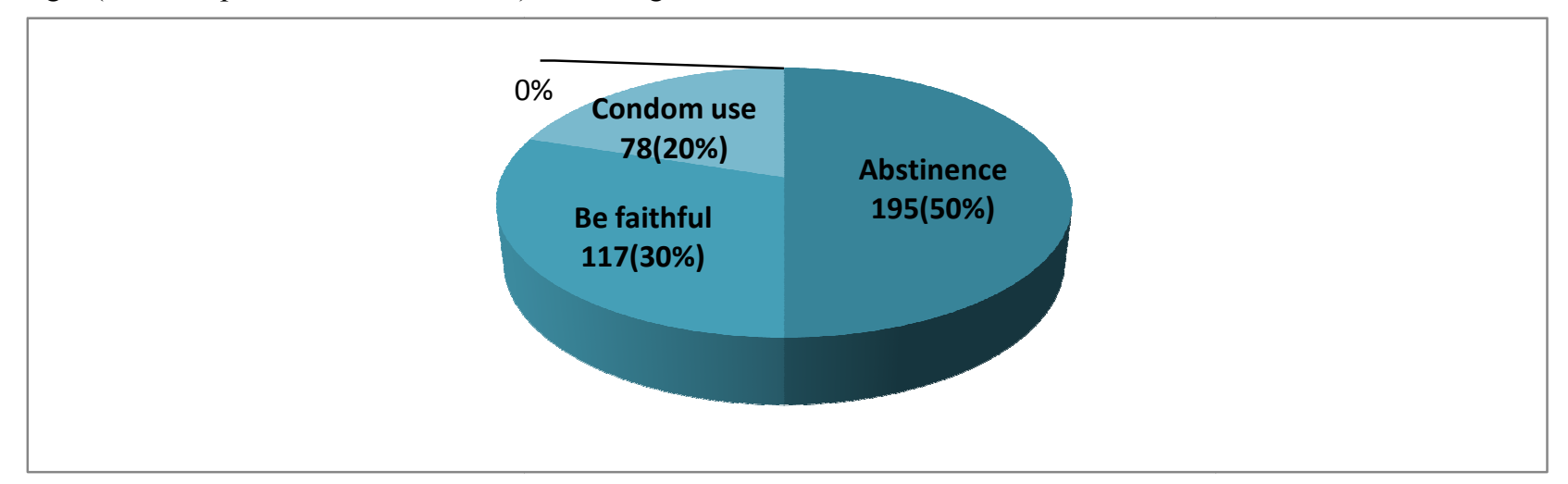

Figure 1. HIV/AIDS prevention method preference among students in Debre Berhan University, May 2013 GC.

The respondents were also asked which prevention method that they think the safest prevention method for university and higher educational institute students. 190(48.72\%) of them reported Abstain from sex as the safest prevention method followed by proper Condom use $133(34.1 \%$ ) and be faithful to one partner $67(17.18 \%)$. They also further asked for their opinion on the prevention method which most students of this university were currently applying. According to this $307(78.72 \%)$ of the respondents were reported condom use as the most currently applied method of prevention in Debre 
Berhan University followed by abstinence and be faithful $47(12.05 \%)$ and $36(9.23 \%)$ respectively. The figure 2 , below shows that the students opinion about the type of prevention method which reported as the safest and which the DBU students were currently applied.



Figure 2. Students opinion on the type of prevention method which they reported as the safest and currently applied prevention method by DBU students, May $2013 G C$.

As the table 2 below describes the relationship between socio demographic statuses of the respondents with their favored prevention method. According to this $75 \%$ of $4^{\text {th }}$ year students want to be used condom.

Table 2. Students HIV infection prevention method preference in accordance with their Socio demographic status in Debre Berhan University, May 2013 GC.

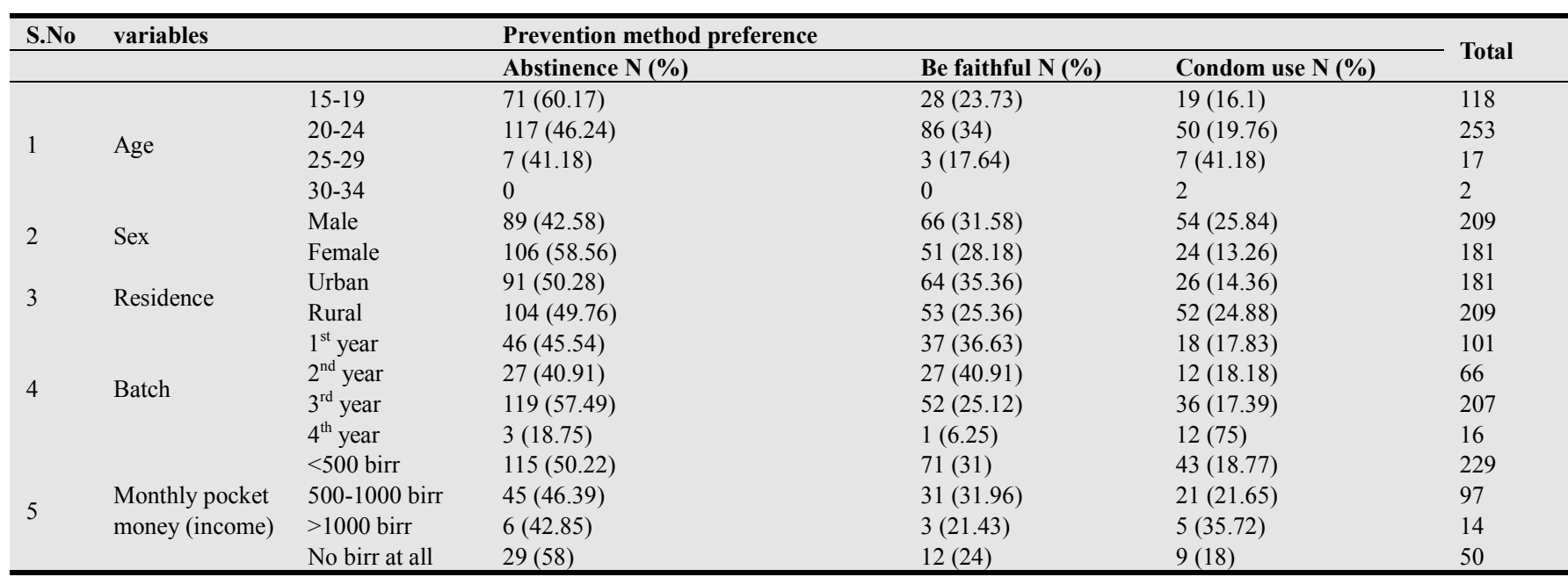

Regarding to presence of sexual partner among 390 respondents 233(59.74\%) had no sexual partner and $157(40.26 \%)$ had sexual partner. Among those who had sexual partner, 114(72.61\%) had one sexual partner, 18(11.46\%) two, $8(5.1 \%)$ three and $17(10.83 \%)$ had more than three partner. Again among those who had sexual partner 82(52.23\%) used condom followed by be faithful to their sexual partner $67(42.68 \%)$ and $8(5.1 \%)$ neither of the two. $90(57.32 \%)$ of the respondent who had sexual partner reported that abstinence from sex was difficult to use with their sexual partner. They all reason out that abstinence from sex ends with fade up and it is difficult to implement with their sexual partner. The other $25(15.92 \%)$ respondents stated that be faithful with one partner is difficult to implement. One of their reason was fearing of that their partner may have sexual experience with another person $13(52 \%)$, and the rest $12(48 \%)$ of them stated their reason as they already have more than one sexual partner and difficult to restrict their sexual need to one partner.
$18(11.46 \%)$ respondents reported condom as difficult to use with their sexual partner. $12(66.68 \%)$ of them reason out that their partner didn't allow using Condom, 3(16.66\%)said that it decrease satisfaction and $3(16.66 \%)$ their religion didn't allow using condom. The rest $24(15.29 \%)$ of the respondents who had sexual partner reported that there was no difficulty to use all the three prevention method with their sexual partner.

Among the total respondents $206(52.82 \%)$ had past sexual experience and $184(47.18 \%)$ had no sexual experience before. From those who had past sexual experience, 52(26.21\%) had sex before they join the university, 54(26.21\%) had sexual experience after they entered the university and 100(48.54\%) had sex in both occasions. Those respondents also asked whether their past sexual experience affect their current prevention method preference or not. According to this, $140(67.96 \%)$ responded as their past sexual experience had influence on their current prevention method choice. In stating out the influence of past sexual experience; $91(65 \%)$ of them 
reason out its influence as, after their past sexual experience they faced difficulty to abstain, 45(32.15\%) states that after their past sexual experience they faced difficulty to abstain to one partner and the remaining $4(2.85 \%)$ influence to have more sexual partner and use condom with them.

Regarding to Khat/alcohol or other drug use status of the respondents $62(15.90 \%)$ used Khat/ alcohol or other drug. From those respondents who used Khat/ alcohol or other drugs $17(27.42 \%)$ of them used once a week, followed by once a month $25(40.32 \%)$, once in every other day 16 (25.81\%) and every day $4(6.45 \%)$. They also further asked the influence of Khat/ alcohol or other drugs use in their prevention method choice and $22(35.5 \%)$ responded as use of those drugs had influence on their prevention method preference and the remaining $40(64.5 \%)$ reported that it had no influence.
Regarding to watching pornographic movies 94(24.1\%) of the total respondents watched pornographic movies repeatedly. From those $61(64.9 \%)$ of them responded that watching pornographic movies repeatedly had influence on their prevention method preference and the remaining 33 (35.1\%) reported that it haven't influence on their prevention method preference. Among those respondents who responded that watching pornographic movies had influence on their prevention method choice, $33(54.1 \%)$ of them reason out that watching pornographic movies repeatedly influenced them to have sexual partner and have sex with their sexual partner, $20(32.8 \%)$ to have sex and use condom and the rest $3(4.9 \%)$ report that it influenced them to have sex even with a person which they didn't know before.

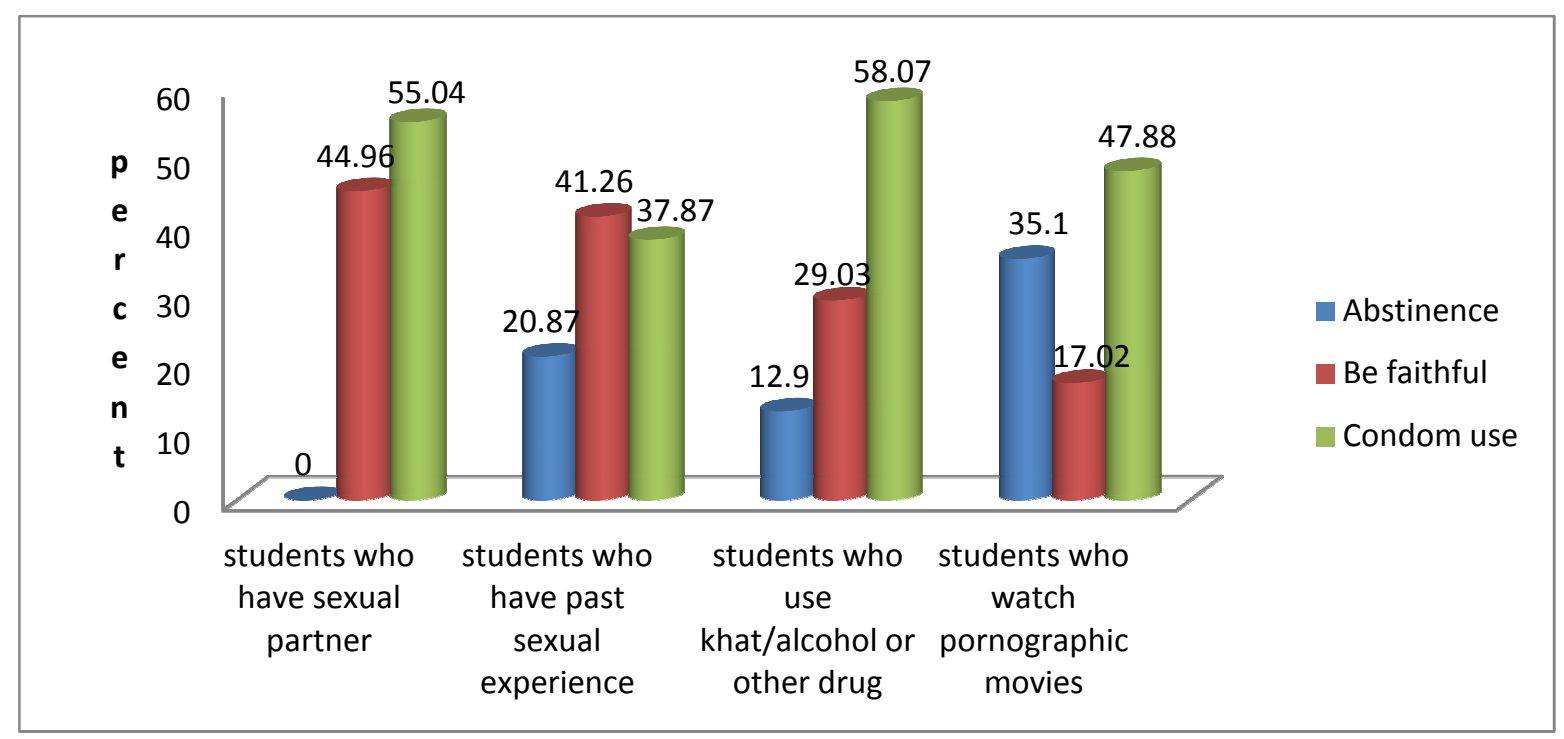

Figure 3. HIVIAIDS prevention method preference among students in accordance with different behavioral characteristics in Debre Berhan University, May $2013 G C$.

Among the total respondents $64(16.41 \%)$ of them reported that their monthly pocket money had influence on their prevention method choice and the remaining 326(83.59\%) respond that their income had no influence on their choice of prevention method. The respondents also asked that whether their religious affairs had influence on their prevention method preference or not. 157(40.26) reported that their religious affairs had influence on their prevention method preference and 233(59.74\%) stated as it had no influence $.134(85.35 \%)$ of them reason out the influence of their religious affairs as their religion recommend abstain from sex before marriage and 23(14.65\%)respondents as their religion didn't allow using condom.

Table 3. Association between some selected variables with abstinence among Debre Berhan University, May $2013 G C$.

\begin{tabular}{|c|c|c|c|c|c|c|c|}
\hline S.No & Variables & & Abstinence & $\mathbf{P}$ & $X^{2}$ & OR & Df \\
\hline 1 & Sex & $\begin{array}{l}\text { Female } \\
\text { Male }\end{array}$ & $\begin{array}{l}106 \\
89\end{array}$ & $<0.005$ & 9.92 & 1.92 & 1 \\
\hline 2 & $\begin{array}{l}\text { Watching pornographic } \\
\text { movies }\end{array}$ & $\begin{array}{l}\text { No } \\
\text { Yes }\end{array}$ & $\begin{array}{l}296 \\
94\end{array}$ & $<0.005$ & 10.98 & 2.22 & 1 \\
\hline 3 & $\begin{array}{l}\text { Monthly pocket money } \\
\text { (income) }\end{array}$ & $\begin{array}{l}\text { No birr at all } \\
<500 \\
500-1000 \\
>1000\end{array}$ & $\begin{array}{l}229 \\
97 \\
14 \\
50\end{array}$ & $<0.025$ & 9.5 & $\begin{array}{l}1.00 \\
1.2 \\
1.4 \\
1.4\end{array}$ & 3 \\
\hline
\end{tabular}

Interpretation of the association;

1. Being female are more likely favored to be abstain from sex than being male $\left(\mathrm{X}^{2}=9.92, \mathrm{P}<0.005, \mathrm{CI}=95 \%\right)$.

2. Students who don't engage in watching pornographic movies are more likely eager to prefer abstaining from sex than those who watch pornographic $\operatorname{movies}\left(\mathrm{X}^{2}=10.98, \mathrm{P}<0.005, \mathrm{CI}=95 \%\right)$.

3. Students having relatively low amount of pocket money 
per month are more likely eager to prefer abstaining from sex than who they gain more money $\left(\mathrm{X}^{2}=9.5\right.$,

$\mathrm{P}<0.025, \mathrm{CI}=95 \%)$.

Table 4. Association between some selected variables with be faithful among Debre Berehan University, May $2013 G C$.

\begin{tabular}{llllllll}
\hline S.No & Variables & & Be faithful & P & $\mathbf{X}^{\mathbf{2}}$ & OR & Df \\
\hline \multirow{2}{*}{1} & Past sexual & Yes & 206 & $<0.005$ & 25.57 & 3.34 & \multirow{2}{*}{1} \\
& experience & No & 184 & $<4$ & \\
\hline
\end{tabular}

Interpretation of the association;

Students who have past sexual experience are more likely want to be abstaining from sex than who didn't have experience before $\left(\mathrm{X}^{2}=25.57, \mathrm{P}<<0.005, \mathrm{CI}=95 \%\right)$.

Table 5. Association between some selected variables with condom use among Debre Berhan University, May $2013 G C$.

\begin{tabular}{|c|c|c|c|c|c|c|c|}
\hline S.No & Variables & & Use condom & $\mathbf{P}$ & $\mathbf{X}^{2}$ & OR & Df \\
\hline 1 & Khat/alcohol or other drug use & $\begin{array}{l}\text { Yes } \\
\text { No }\end{array}$ & $\begin{array}{l}62 \\
328\end{array}$ & $<<<0.005$ & 54.3 & 8.24 & 1 \\
\hline 2 & Watching Pornographic movies & $\begin{array}{l}\text { Yes } \\
\text { No }\end{array}$ & $\begin{array}{l}94 \\
296\end{array}$ & $<<<0.005$ & 58.9 & 7.32 & 1 \\
\hline 3 & Past sexual experience & $\begin{array}{l}\text { Yes } \\
\text { No }\end{array}$ & $\begin{array}{l}206 \\
184\end{array}$ & $<<0.001$ & 80.14 & 5.62 & 1 \\
\hline 4 & Residence & $\begin{array}{l}\text { Urban } \\
\text { Rural }\end{array}$ & $\begin{array}{l}181 \\
209\end{array}$ & $<0.025$ & 6.44 & 2.08 & 1 \\
\hline
\end{tabular}

Interpretation of the association;

1. Students who use Khat/alcohol or other drug are more likely willing to use condom than who don't use Khat/alcohol or other $\operatorname{drug}\left(\mathrm{X}^{2}=54.3, \quad \mathrm{P}<<<0.005\right.$, $\mathrm{CI}=95 \%$ ).

2. Students who engage in watching pornographic movies are more likely favored to use condom than who don't watch it $\left(\mathrm{X}^{2}=58.9, \mathrm{P}<<<0.005, \mathrm{CI}=95 \%\right)$.

3. Students who have past sexual experience are more eager to use condom than who didn't have experience before $\left(\mathrm{X}^{2}=80.14, \mathrm{P}<<0.001, \mathrm{CI}=95 \%\right)$.

4. Students who come from urban areas are more likely preferred to use condom than those who come from rural area $\left(\mathrm{X}^{2}=6.44, \mathrm{P}<0.025, \mathrm{CI}=95 \%\right)$.

\section{Discussion}

Regarding to preference of the three well known HIV/AIDS infection prevention methods, comparing the Western and Europe university student's status with our country result significant gap .In this study from the total 390 respondents $195(50 \%)$ of the respondents preferred abstinence as their top prevention method against HIV infection followed by $117(30 \%)$ be faithful to their partner and the remaining $78(20 \%)$ prefer to use condom consistently and properly during their sexual act. Whereas another finding, the research conducted on J.B Elgar University, Department of Medicine, in USA, showed that among the total of 3651 university students who have heard about HIV/AIDS, 2375(65.05\%) were prefer to use condom properly, $814(22.3 \%)$ be faithful with their partner, $165(4.52 \%)$ prefer to use abstain before marriage and the rest $297(8.12 \%)$ were didn't want to use none of the above methods. Possible reasons for the gap between may be: Firstly as the later research was done on Medical students, who had significantly enough information about HIV/AIDS, such as knowing the numerical data on the likelihood of HIV transmission per sexual act, with or without condom, may relief the students from fearing about HIV and eager to use condom rather than to be abstain from sex. Secondly, low prevalence of HIV in Western and Europe countries may have influence on their prevention method preference. Also Study finding on students on University of Zululand, Swithrland shows incompatible result with our study. It states the student's prevention method preference as $68 \%, 19.6 \%$ and $12.3 \%$ condom use, abstinence and be faithful respectively $(4,5,6)$. But this study revealed that $50 \%$, $30 \%$ and $20 \%$ for abstinence, be faithful and condom use respectively.

When inward our focus to our country, study on 606 students on AAU, one of the oldest and biggest university in Ethiopia, showed that more than half $(52.4 \%)$ of the students prefer abstinence as top prevention measure $(13,14,15)$ which was almost the same with this study result. Also study on WolaitaSodo University, one of newly built university in Southern Ethiopia, from the total 750 undergraduate students which the study incorporates $97.3 \%$ had good knowledge about HIV/AIDS. From those respondents $46.7 \%$ take abstinence as their top prevention measure followed by $30 \%$ consistent and proper condom use, $23.3 \%$ be faithful to one sexual partner (16). Comparing the result with this study, there was proximity on the percentage of students who have knowledge about HIV/AIDS, which was $99.49 \%$ in our finding and percentage of abstinence but some variation on prevalence of be faithful and use condom among the students. Possible reason for this gap may be the difference between socio demographic status and behavioral characteristics of the respondents of the two study areas.

Age wise, in this study, $64.87 \%$ of the respondents fall in the age group of 20 to 24 . From this age group $46.24 \%$ states abstinence as their top prevention method against HIV infection. Finding on AAU showed that $77.1 \%$ of the respondents were fall in the age range of 20 to 24. Among 
those respondents majority of them $(53.2 \%)$ were stated that abstain from sex was the top prevention method they taken. In relation with the students residence with their prevention method choice, this study revealed that from those respondents who choice condom, $33.34 \%$ were join the university from urban area, 66.66\% were from rural area. Again from those respondents whose prevention method was abstinence $53.33 \%$ joined the university from rural areas and the rest $46.67 \%$ are from urban areas. Finding on WolaitaSodo University revealed that among those students who respond as condom use as their option of prevention $58.2 \%$ were join the campus from urban area and the remaining $41.8 \%$ were from rural areas. And also from those respondents who said that abstinence as their top prevention measure $67.9 \%$ of them were came from rural area and 32.1 were from urban area (16). This gap may the result of the difference between the socio demographic statuses of the two study areas.

In relation with past sexual experience, this study shows $206(52.8 \%)$ of the respondents had past sexual experience before or after they join the university or in both occasions. Of them who had sexual experience, $140(67.96 \%)$ reported as their experience have influence on their prevention choice currently. But $43.6 \%$ of respondents in WolaitaSodo University had past sexual experience and of them $26.2 \%$ reported that their past sexual experiences have influence on their current HIV infection prevention measure $(16,17,18)$. The possible reason for this gap may be the difference between the duration of time in which past sexual experience was asked. This means on this study past sexual experience was asked without period limit but in WolaitaSodoUniversity the question was forwarded for the respondent within 12 months period prior to the study. In this study $83.59 \%$ of the total respondents reported as income have no influence. Also in WolaitaSodo University, $72.1 \%$ of them were reported that their monthly pocket money have no influence on their prevention method choice $(16,17)$. This shows that monthly pocket money have no influence on their prevention method choice.

Income wise, among all respondents 97 students have gain pocket money between 500 - 1000 birr monthly and from those students $45(46.39 \%)$ prefer to be abstain, 31(31.96\%) be faithful and 21(21.65\%) use condom properly. Comparing this finding with the research done in AAU students among 60 $(9.9 \%)$ respondents who gain monthly pocket money between $500-1000$ birr, 23(38.33\%) of them preferred to be abstain from sex, 19(31\%) used condom properly and the remaining $18(30.67 \%)$ wants be faithful to their partner (15).

In this study regarding to watching pornographic movies, from the total respondents $94(24.1 \%)$ were engaged in viewing pornographic movies and from those 45(47.88\%) preferred condom use, followed by abstain from sex and be faithful $33(35.1 \%)$ and $16(17.02 \%)$ respectively. This study also shows that there is significantly high association between watching pornographic movies with condom usage $\left(\mathrm{X}^{2}=58.9\right.$, $\mathrm{P}<<<0.005)$. On the other hand, the research finding in AAU students from the total 606 respondents 236(38.9\%) were engage in viewing pornographic movies and of them
$130(55.2 \%)$ preferred to use condom, $79(33.68 \%)$ be faithful to once partner and the rest $27(11.12 \%)$ preferred to be abstain themselves from sex. The study also revealed that repeated exposure for those pornographic films had significantly associated with condom usage $(\mathrm{AOR}=2.51$, CI $(0.72-4.39)$, $\mathrm{p}<0.001)(15,16,17,18)$.

In this study we investigate that those respondents who have the habit of Khat/alcohol or other drug usage are highly significant association with condom usage than those who don't use such a drug $\left(\mathrm{X}^{2=} 54.3, \mathrm{P}<<<0.005\right)$. Also the research finding in AAU showed that, there was significantly high association between Khat chewing habit with condom usage $(\mathrm{AOR}=3.05$, CI $95 \%(1.75-5.26) \mathrm{p}<0.001)$. This implies that Khat chewing have significantly high association with condom usage.

\section{Conclusion}

Half of students in Debre Berhan University prefer to use Abstinence from sex in order to protect themselves from HIV/AIDS infection. Being female, not engaging in watching pornographic movies repeatedly and relatively low monthly pocket money (income) are highly determinant factors for the students to be Abstain. Khat/ alcohol or other drug use, engaging in watching pornographic movies repeatedly, having past sexual experience and came from urban areas are highly determinant factors for the students to use condom. Even though most of the respondents are agreed that to do abstain from sex is the safest prevention method for University and higher education institutions, $78.72 \%$ of the students stated Condom use as the applicable method of prevention for this university.

\section{Author's Contributions}

$\mathrm{KG}$, have made substantial contributions to beginning and design, collection of data, analysis and interpretation of data and in drafting the manuscripts and correcting the comment given by the advisors.

TM involved in revising the research paper and the manuscript critically for important intellectual context and approval of the final version to be published and participated in its design and coordination. He participated in the approval and funding process, participated in the design of the study participated in its design and coordination.

$\mathrm{MH}$, involved in revising the research paper and the manuscript critically for important intellectual context and approval of the final version to be published and participated in its design and coordination.,

AAG, YYA, AWH, and MKA had greater contribution in reviewing the manuscript English and topography. And helped to draft the manuscript.

\section{Acknowledgements}

We are thankful to all our department technical staffs for their excellent technical support. We are grateful to all the 
participants for their cooperation and Debre Berhan University for financial support.

\section{References}

[1] Global HIV/AIDS Response (2011). Epidemic and health sector progress towards Universal access. 19:54-66.

[2] Teka, T(2003). College students' Attitude and Knowledge of HIV/AIDS.(1)54.

[3] Alexander H , Cole J (2009). Sexual attitude, orientation and prevention of HIV/AIDS in J.B Elgar University, department of medicine.

[4] Andrew (2008). . Zululand's HIV/AIDS Intervention Strategies. 2: $2-8$.

[5] NHAPCO (2010). The single point estimate for HIV/AIDS in Addis Ababa, Ethiopia. 1 12:37.

[6] Weller S, Davis K(2009). The President's Emergency Plan for AIDS Relief Office of the U.S. Global AIDS Coordinator ,Definition of ABC methods.2009. Washington DC, USA. Second edition.

[7] USAIDS (2004). Report on the global AIDS, $4^{\text {th }}$ global report4:97

[8] Kermyt, G.A (2007).HIV/AIDS prevention knowledge among youth in cape Town.2007, (3): 35-39.

[9] Opio,A (2010).HIV sero-behavioral study in six Universities in Uganda.sep. (18):12-22.

[10] UNAIDS (2006). Report on the global AIDS Epidemics.
United Nations Publications.26:12-14. Shelton J, Halperin D, Nantulya V, Potts M, Gayle H, Holmes K. Partner reduction is crucial for balanced "ABC" approach to HIV prevention 2010,7:19-20

[11] Addis Ababa HIV/AIDS Prevention and Control Office (2011). . Epidemics of HIV/AIDS among higher institute students. 11:23-26.

[12] Beyene, P.,Solomon, B., Yared ,M(2004). AIDS and college students in Addis Ababa; a study of knowledge, attitude and behavior.2004, vol (3):35-38.

[13] Yibeltal Berie, Kasahun Alemu, Alemayehu Belay, Zemichale Gizaw. Factors Affecting Utilization of Insecticide Treated Nets among People Living with HIV/Aids in Bahir Dar City, Northwest Ethiopia. Science Journal of Clinical Medicine. Vol. 2, No. 6, 2013, pp. 147-152. doi: 10.11648/j.sjcm.20130206.11

[14] Abebaw, A (2008).Determinants of voluntary HIV counseling and testing among AAU undergraduate final year students. 4: 4548

[15] Nigatu, R., Seman, K (2011).. Attitudes and practices on HIV preventions among students of higher education institutions in Ethiopia: The case of Addis Ababa University. (6):15-17.

[16] Terefe, G., Tefera, B., Tizita,T(2011). Predicto of sexual abstinence among WolaitaSodo University.4 (5):1-8.

[17] Tesfaye Setegn Mengistu, Abulie Takele Melku. Sexual and Reproductive Health Problems and Service Needs of University Students in South East Ethiopia: Exploratory Qualitative Study. Science Journal of Public Health. Vol. 1, No. 4, 2013, pp. 184-188. doi: 10.11648/j.sjph.20130104.13

[18] NHAPCO (2010). The single point estimate for HIV/AIDS in Addis Ababa, Ethiopia. 12:37. 